\title{
Sex Differences in Self-Concept and Symptoms of Depression During the Transition to College
}

\author{
Corinne Alfeld-Liro ${ }^{1}$ and Carol K. Sigelman ${ }^{2}$
}

Received April 3, 1996; accepted June 29, 1997

In an investigation of sex differences in adaptation to college, real and ideal self-concept and symptoms of depression were studied longitudinally in a sample of 287 students. Survey data were collected at a summer orientation and one semester into freshman year. No sex differences in self-concept were found before college, but males' real self-concept became more positive over the transition. Females were more depressed than males at both times, although depressive symptom scores increased in both sexes. Real self-concept scores were negatively correlated with depressive symptoms in both sexes at both times, while the discrepancy between real and ideal self-concepts was positively correlated with depressive symptoms among females before college and in both sexes midway through freshman year. A one-year follow-up revealed that females' real self-concept scores increased to match those of males by mid-sophomore year. These sex differences are discussed in relation to psychological development during adolescence.

This paper was presented as a poster at the annual conference of the American Psychological Association, New York, New York, August 11, 1995. It is based on a master's thesis by the first author under the direction of the second author at George Washington University. 'Doctoral candidate in the Combined Program in Education and Psychology at the University of Michigan. Received M.A. in developmental psychology from George Washington University. Interests are in adolescent development within the context of schools, particularly achievement motivation, educational and occupational aspirations, and the transition out of high school and into young adulthood. To whom correspondence should be addressed at 5201 Institute for Social Research, P. O. Box 1248, University of Michigan, Ann Arbor, Michigan 48106-1248.

${ }^{2}$ Professor of Psychology at George Washington University. Received Ph.D. from George Peabody College of Vanderbilt University. Interests are in social development in childhood and adolescence, particularly the development of understandings of health issues, prejudice and stigmatization, and social comparison processes. 


\section{INTRODUCTION}

Erik Erikson (1968) called the adolescent task of identity formation a "crisis" because physiological, cognitive, and social changes coincide at the point when the adolescent begins to make important life decisions. This "crisis," while fueling new growth and awareness, also brings vulnerability at a time when focus on the self is at its developmental height. While there has been much research on adolescent self-esteem, findings are inconsistent, sometimes revealing major change but often showing that self-esteem is fairly stable or that whatever instability exists occurs early and is temporary. Furthermore, when sex differences surface in these studies, males consistently demonstrate higher levels of self-esteem than females. What is lacking in the research, however, is a specific focus on changes in selfconcept and well-being during life transitions, times that are especially likely to be characterized by flux.

Repeated assessment of self-perceptions during a single, major life transition during adolescence may reveal temporary fluctuations that are not apparent in broad longitudinal studies. This study explores an important time in the development of many late adolescents: the transition to college. College is a time when setting goals for the future and forming an "ideal self" are key developmental tasks, when adolescents leave familiar people and settings and adjust to new ones, and when changes in well-being and perceptions of self may be expected. This study focuses on changes in the real and ideal self-concepts of young men and women as they make the transition to college and the implications of these changes for students' psychosocial adjustment, as indicated by their experience of symptoms of depression. What are the patterns of change, and are they different for women and men?

\section{Definition of Self-Concept}

The construct of self-concept, as defined by some researchers (see Cantor et al., 1987), includes the "real self" (one's idea of what one really is), the "ideal self" (a realistic image of what one would like to be), and the discrepancy between the two. Self-concept discrepancy, then, is where one stands (real self) in relation to where one would like to be (ideal self). It has been suggested both that this discrepancy can motivate self-improvement (to reduce the gap between real and ideal self) and that it can cause sadness or disappointment (Higgins, 1987). In fact, a large discrepancy between real and ideal self-concepts has been linked to depression among college students (Blatt et al., 1976; Higgins et al., 1985). Studies such as 
these are important in that they go beyond traditional attempts to correlate global self-esteem and depression. However, they do not tell us which aspect of the self-concept (real, ideal, or discrepancy) has the strongest relationship to depression. Is depressive affect during the college transition associated with a drop in real self-concept, higher ideals in the face of new opportunities, or both? It is necessary to examine all three components of self-concept in relation to symptoms of depression in order to understand their patterns of association. Furthermore, relationships may differ over time or by sex, so that a longitudinal study examining males and females separately, as they develop, becomes important.

\section{Sex Differences and Changes in the Self-Concept During Adolescence}

As Simmons (1987) argues, dramatic discontinuity in the environment during adolescence can produce changes in both self-concept and psychological distress. A good deal of research supports her claim, but little of it has examined sex differences in both real and ideal self-conceptions during critical adolescent transition periods.

\section{Early to Middle-Adolescence}

Studies of self-esteem and well-being during the transition to junior high school have found that boys tend to fare better than girls (e.g., Abramowitz et al., 1984; Eccles et al., 1989; Eccles et al., 1993; Wigfield et al., 1991; Hirsch and Rapkin, 1987; Simmons, 1987; Simmons et al., 1987). This may be because girls mature earlier than boys and often experience the junior high transition at the same time as the changes of puberty. In fact, Simmons and her colleagues (1987) found that girls experience a drop in self-esteem to the extent that they are experiencing a large number of concurrent changes. The number of "life-transition stressors" is higher for girls than for boys at this time, contributing to girls' lower levels of self-esteem (Simmons et al., 1987). Furthermore, a review of the literature by Simmons (1987) showed that girls who experience multiple stressors in early adolescence do not recover from these losses by mid-high school (see also Petersen et al., 1991).

In high school, others have found that girls experience a greater number of stressful life events than boys, although both sexes experience an increase in these events from freshman to senior year (Gröer et al., 1992). However, studying the transition from junior high to high school, Barone et al., (1991) found that girls had less difficulty than boys in adapting to 
the high school environment, as indicated by a smaller drop in GPA and less difficulty with new social environment tasks after the transition. It may be that this later transition coincides more with puberty for boys than for girls. These findings suggest that adolescent transitions occurring at different points in development may affect boys and girls differently.

\section{Late Adolescence/College}

Researchers studying the transition to college (Erwin, 1982) and changes during college (Hood et al., 1986; Hesse-Biber and Marino, 1991) have also found that men tend to fare better than women in terms of selfimage. During the transition in particular, females have been found to adapt less quickly than males (Stewart et al., 1986) and experience more stress and psychological disturbance than males (Fisher and Hood, 1988) after entering college. Hesse-Biber and Marino (1991) have suggested that this may be because women are more susceptible to psychological disturbance during the college transition.

Yet others (e.g., Loeb and Magee, 1992) report similar patterns of disruption and then rebound in self-perceptions in both sexes. Findings are inconsistent, then, regarding whether women are more vulnerable than men during the college transition, as they are during the junior high school transition, to significant changes in self-perception.

\section{Self-Concept Discrepancy, Maturation, and Depression}

Little of the work on changes in the self during adolescent transitions has examined real and ideal selves and the discrepancy between them. Cognitive developmentalists have noted that self-concept discrepancies typically increase with age from childhood through adolescence and have suggested that this is a result of the cognitive differentiation that comes with maturity (Bybee and Zigler, 1991; Katz et al., 1975). Girls, who mature physically earlier than boys, may also show earlier psychological maturation, as indicated by greater self-concept discrepancies. Indeed, several researchers have found that girls have wider discrepancies than boys between early adolescence and early adulthood, either because girls had higher ideal self-concepts (Schludermann and Schludermann, 1986) or because males had gradually increasing real self-concepts, which narrowed their self-concept discrepancies (Block and Robins, 1993). Females have also been found to have wider self-concept discrepancies than males in several studies of college students (Boggiano and Barrett, 1991; Higgins et al., 1985; O'Connor, 1978). 
But real-ideal discrepancy, although in part a product of cognitive maturation, is not necessarily a sign of psychological adjustment. Bybee and Zigler (1991) found that the cognitively more mature students in their sample (who also had the highest discrepancy scores) scored higher on a measure of guilt than did their less-developed counterparts. This guilt was associated with a positive ideal self-image rather than with a negative real self-image. Thus, it would seem that females' higher ideals, perhaps reflecting the multiple "ideal" roles adult women must fulfill, including work and family (Bardwick, 1971; Higgins et al., 1985) could contribute to more guilt feelings. Bybee and Zigler (1991) note that guilt is associated with anxiety, disappointment, and self-hatred (see also Blatt et al., 1976). Other researchers have found self-concept discrepancies and depression to be correlated in college students (Higgins et al., 1985) and higher in college women than men (Boggiano and Barrett, 1991).

It has been suggested that females have less healthy, or less adaptive, forms of coping with stressors than do males, which may account for their higher levels of depression. Specifically, females tend to attribute failures to internal, stable, and global factors more often than do males (Boggiano and Barrett, 1991). Furthermore, females use rumination as a form of coping whereas males distract themselves with activity to cope with stressful events, which Nolen-Hoeksema (1990) suggests is a reason why women experience longer and more intense bouts with depression than do men. This "maladaptive" coping style may stem from societal messages to females about the kind of behavior that is favored; specifically, blaming oneself, not making waves, and other forms of "internalizing" mechanisms, which are more consistent with a female sex role, as opposed to males' tendency to "externalize" by projection or turning against others, which is more consistent with a male sex role (Petersen et al., 1991).

Thus, adolescent females' larger self-concept discrepancy scores could be either a sign of psychological maturation, an indicator of their less healthy self-images relative to males, or both. A direct examination of the correlations over the college transition between depression and real and ideal self-concept scores-not just discrepancy scores-would clarify this issue. If a developmental process is at work, females may experience a widening gap between their real and ideal selves earlier than males, but males should "catch up" at the start of young adulthood as they reach cognitive maturity as well.

\section{Sex Differences in Depression}

Allgood-Merten et al. (1990) found that depression was correlated with low self-esteem among ninth through twelfth graders, and that girls in all 
the grades reported more symptoms of depression and more recent stressful events than boys. Yet, Nolen-Hoeksema (1990), in her review of the research on depression, concluded that there were fewer findings of gender differences in depression among college students than in any other age range or than among noncollege youth the same age. Indeed, while Gladstone and Koenig (1994) found that females were more depressed than males in a high school sample, this sex difference was not evident in a separate college sample. Nolen-Hoeksema (1990) and Gladstone and Koenig (1994) have suggested that this is due to college women's experience of more gender equality and fewer environmental stressors compared to non-college women. As noted earlier, however, other studies suggest that the college transition may be uniquely distressing to women, as least temporarily (Fisher and Hood, 1988; Stewart et al., 1986). Moreover, Boggiano and Barrett (1991) found that college females had both greater levels of depressive symptomatology and greater real-ideal discrepancy scores than males.

In summary, previous work suggests that self-concept discrepancy increases with age and is linked to low self-esteem and high levels of depression, that depressive symptoms are more common among females than males, and that females have higher self-concept discrepancy scores than males. Based on such findings, we propose that, if women have more discrepant self-concepts than men at the transition to college, whether for maturational or other reasons, they may be more vulnerable to negative changes in self-perception and increased depression at this time. Young men may experience similar changes linked with maturation, but may experience them later and less dramatically.

\section{Hypotheses}

This study examines changes in self-concept and symptoms of depression experienced by women and men during the transition to college (defined as the period beginning the summer after high school and ending after the freshman year of college). Rather than assessing only global selfesteem or only ideal-real discrepancy, however, we examine changes in the real self, ideal self, and ideal-real discrepancy separately in order to gain insight into which aspects of the self are most vulnerable to change during this important developmental transition and which have the greatest implications for well-being. Unlike most studies of college adjustment, this one assesses students before they entered college (Time 1, June orientation), as well as one semester after their arrival (Time 2, January of freshman year). Data gathered from a reduced sample of these students midway 
through their sophomore year (Time 3) are also analyzed to shed light on the stability of any transitional changes observed. Seven hypotheses regarding the Time 1 to Time 2 transition were derived from the literature.

\section{H1: Time 1 Sex Differences}

We hypothesize that males will enter college with more positive (higher) real self scores than females (Block and Robins, 1993; Cairns et al., 1990; Erwin, 1982). Girls will exhibit an earlier maturation of the selfconcept than boys, demonstrated by greater ideal-real self-concept discrepancies at entrance to college (Boggiano and Barrett, 1991; Bybee and Zigler, 1991; Higgins et al., 1985; O'Connor, 1978), largely due to their having more positive (higher) ideal selves (Schludermann and Schludermann, 1986).

\section{H2: Changes in Males}

An increase in males' ideal-real self-concept discrepancy from Time 1 to Time 2 will be characterized by a decrease in real self-concept (Boggiano and Barrett, 1991; Eccles, 1987; Erwin, 1982) and an increase in ideal selfconcept. An increase in ideals when entering college may be associated with rapid adaptation to the college environment (Stewart et al., 1986).

\section{H3: Changes in Females}

Women's ideal self-concepts are expected to drop after entering college, perhaps as they realize, through messages sent by society, that achieving their high ideals will be difficult (Beil, 1992), and this drop in females ideals will be accompanied by a drop in real self-concept (Boggiano and Barrett, 1991; Eccles, 1987).

\section{H4: Sex Differences in Changes}

Based on the above, it is predicted that there will be a sex difference in change in discrepancy scores from Time 1 to Time 2, due mainly to males' experience of a more positive change in ideal self scores than females. Therefore, the change in males' discrepancy scores is predicted to be larger than females'. 


\section{H5: Sex Differences in Symptoms of Depression}

Because of their greater ideal-real discrepancies (Boggiano and Barrett,1991; Bybee and Zigler, 1991; O'Connor, 1978; Schludermann and Schludermann, 1986) and vulnerability during school transitions (Eccles et

al., 1989; Hesse-Biber and Marino, 1991; Simmons et al., 1987), females are expected to be more depressed than males prior to college entrance (Time 1) and especially following it (Time 2).

\section{H6: Correlations of Self-Concept Scores and Symptoms of Depression}

Those students whose self-concept discrepancy scores are large are hypothesized to show the most symptoms of depression at each point of measurement, stemming from dissatisfaction with their actual selves in comparison to their aspirations (Garg, 1992; Higgins et al., 1985). Since low self-esteem and depression are related (e.g., Allgood-Merten et al., 1990; Rosenberg, 1986), it is expected that real self-concept will be negatively correlated with symptoms of depression. Ideal self-concept, on the other hand, will be positively correlated with depressive symptoms, since the more out of reach goals are, the more likely one is to blame oneself for not living up to them (Bybee and Zigler, 1991).

\section{H7: Sex Differences in Self-Concept/Depression Correlations}

Based on evidence that self-perceptions may be more closely linked to well-being in females than in males, correlations between real self-concept and symptoms of depression and between self-concept discrepancy and symptoms depression are expected to be stronger for females (Boggiano and Barrett, 1991; Hesse-Biber and Marino, 1991). This could also be accounted for because of a greater variance among the females.

\section{METHOD}

\section{Participants}

This study analyzes the responses to a repeated survey of 287 students (128 males and 159 females) from the class of 1996 at a private, urban university on the East coast. Students' years of birth ranged from 1969 to 1975 , and the average age at the time entrance to college in the summer of 1992 was 18.25 . The majority of the participants (73\%) were Caucasian, 
$14 \%$ were Asian, $5 \%$ were African American, and $8 \%$ were of other ethnic backgrounds. Their parents were generally well educated and wealthy, with $25.4 \%$ of mothers and $40.2 \%$ of fathers having received a graduate or professional school degree. Only $12 \%$ of families had incomes less than $\$ 25,000$ per year, $42.7 \%$ had incomes of $\$ 25,000-\$ 75,000$ per year, and fully $54.3 \%$ had incomes over $\$ 75,000$ per year. However, these figures were all self-reported by the students and must be interpreted cautiously.

\section{Survey and Measures}

A questionnaire was completed at each of two points during the college transition: at a June orientation, almost 3 months prior to students' enrollment in college (Time 1) and seven months later, in January of the students' freshman year in college (Time 2). We assume that the period of transition to college begins around the end of the senior of high school and ends somewhere during or after the freshman year of college. Our Time 1 and Time 2 administrations roughly span this transition period.

\section{Sherwood Self-Identity Questionnaire}

The entire survey, in which the scales used in this study were embedded, was originally meant as a general survey of the class of 1996 when they entered the university. The university researchers who adapted the scales did so in order to keep the entire survey to a reasonable length. Two scales from the survey are the focus of this study. The first scale measures real and ideal self-concept and was adapted from Sherwood's (1965) 26-item scale. Seven semantic-differential items were used: academically outstanding vs. academically poor, emotionally healthy vs. emotionally unhealthy, display strong leadership ability vs. lack leadership ability, popular with same sex vs. unpopular with same sex, popular with opposite sex vs. unpopular with opposite sex, intellectually self-confident vs. lack intellectual self-confidence, and socially self-confident vs. lack social self-confidence. These items were thought to be the most important issues from the Sherwood scale for assessing self-concept in a university-wide survey because they tap issues of importance to incoming college students.

On both the Time 1 and Time 2 questionnaires, students were given a 1-7 scale between each adjective pair with the following instructions: "Rate yourself on each of the following traits as compared with the average person your age." The Time 1 questionnaire subsequently read: "Please make both an $\mathrm{X}$ indicating your present picture of yourself and an $\mathrm{O}$ for 
your aspired picture of yourself." The Time 2 questionnaire read: "Please make an X indicating your present picture of yourself," and on the next page, preceding a separate but identical set of items, "Please make an X indicating your ideal picture of yourself." That is, the real and ideal scales were separated on the Time 2 questionnaire, while they were marked on the same scale on the Time 1 questionnaire. The scales were separated at the second administration because many students did not read the instructions carefully at Time 1 and marked only their real selves (these students' surveys were not used). This slight change in the survey at Time 2 was made for ease of interpretation by the students and therefore eliminated possible missing or incorrect data. The final sample used in this study contained only those students who marked their surveys correctly at both survey administrations. We acknowledge that the different formats at Time 1 and Time 2 is a weakness of this study.

Real and ideal self scores were each averaged across the seven items in the scales, so that each participant had one overall real self score and one overall ideal self score. These scores could range from 1 to 7 . High scores indicate a more positive self-concept while low scores indicate a more negative self-concept. The difference between real and ideal scores was calculated by subtracting real from ideal for each item and then averaging these differences to form an overall ideal-real discrepancy score that could range from 0 to 6 . Larger discrepancy scores indicate a greater dissatisfaction with self. Coefficient alphas were acceptable: .79 for real self, .90 for ideal self, and .87 for the discrepancy between real and ideal selves at Time 1, and .84 for real self, .92 for ideal self, and .86 for the discrepancy at Time 2.

\section{Beck Depression Inventory}

The depression scale is an adaptation of the Beck Depression Inventory (BDI; Beck, 1967), which taps both affective and physiological symptoms of depression. The original scale is composed of 21 items and has been shown to be reliable and valid for use with college students (Beck, 1967; Bumberry et al., 1978, cited in Handal et al., 1987). It was necessary to reduce the BDI in order to keep the longer freshman survey a to a reasonable length. Eight of the original items were used in the present study - those concerning sadness, pessimism, self-accusations, suicidal tendencies, crying, insomnia, fatigue, and anorexia-and items concerning loneliness and heaviness of limbs were added to yield a ten-item scale. These items were thought to be the most salient symptoms of depression from the original BDI and were deemed by the researchers to be sufficient 
for the purpose of being included as a measure of well-being in the freshman survey. Students used a 7-point scale to indicate how much they were affected by each symptom in the last two weeks. Item scores were averaged to form a total score ranging from 1 (not depressed) to 7 (very depressed). This reduced BDI scale was reliable, with an alpha of .85 at Time 1 and .87 at Time 2 . However, since the items tap only symptoms of depression it must be kept in mind that there is no basis for inferring clinical depression from scores on this scale.

\section{Procedure}

The first questionnaire was administered in June 1992, during an orientation at the University prior to the students' freshman year (Time 1); fewer than $25 \%$ of admitted students were not able attend the orientation, which required a separate trip to campus early in the summer; these students were given the questionnaires when they arrived on campus in the week before classes began. The second questionnaire was completed in freshman English classes during the students' second semester, approximately seven months later (Time 2). Although efforts were made to ensure that each of the 1203 members of the class of 1996 completed surveys, we were only able to collect data for 941 students (79\%) at Time 1 and 633 students (53\% of class; $67 \%$ of the original sample) at Time 2 . Furthermore, there were many students who failed to complete all of the survey items, failed to complete them correctly, or failed to return the surveys. The final sample included only students for whom we had complete data at both times, resulting in an $N$ of 287 (24\% of the class). However, the gender and ethnic breakdowns of this sample were almost identical to those in the population of entering students at this university, ensuring some degree of representativeness. Still, it should be noted that these results are not necessarily generalizable to the class as a whole or to entering college students in general.

\section{RESULTS}

\section{The Transition from High School to College}

Because this study aimed to test seven specific hypotheses, planned contrasts between means were made using $F$ tests in order to test each hypothesis, rather than employing a general $2(\mathrm{sex}) \times 2$ (time) analysis of variance (ANOVA) design. These analyses examined (1) sex differences at 
Table I. Mean Scores on Self-Concept and Depression Scales Over the Transition to College $e^{a}$

\begin{tabular}{lll}
\hline Scale & Time 1 & Time 2 \\
\hline Real Self & & \\
$\quad$ Females & $4.84(1.02)$ & $4.97(1.05)$ \\
$\quad$ Males & $4.97(0.85)$ & $5.32(0.93)^{c}$ \\
Ideal Self & & \\
$\quad$ Females & $6.31(0.81)$ & $6.42(0.76)$ \\
Males & $6.29(0.85)$ & $6.26(0.89)$ \\
Discrepancy & & \\
Females & $1.48(1.23)$ & $1.45(1.13)^{d}$ \\
Males & $1.32(1.09)$ & $0.94(0.92)$ \\
Depression & & \\
Females & $1.90(0.70)^{d}$ & $2.08(0.77)^{h}$ \\
Males & $1.66(0.56)$ & $1.90(0.71)$ \\
\hline
\end{tabular}

"Statistical comparisons are between males and females within each time point; thus, means should be compared vertically. Time 1 = June 1992, Time $2=$ January 1993. $N=287$ (females $=$ 159 , males $=128$ ) for components of self-concept; $N=285$ (females $=158$, males $=127$ ) for Time 1 depression scale; and $N=282$ (females $=157$, males $=125$ ) for Time 2 depression scale

${ }^{h} p \leq .05$.

$p \leq .01$

$a_{p} \leq .001$.

each point in time, (2) change over time in each sex separately, and (3) sex differences in change over time. Outcome measures in the first set of planned contrasts were real self-concept, ideal self-concept, and discrepancy between the two; depression scores were the outcome measure in a second set of analyses. Means and standard deviations for each of the measures at each point in time are shown in Table I.

Contrary to the hypothesis (H1), there were no significant sex differences in real self, ideal self, or ideal-real discrepancy scores at Time 1, before college. Although ideal self scores did not differ by sex at Time 2, males rated themselves higher (more positively) than females on the real self scale at Time $2, F(1,285)=8.65, p<.01$. Perhaps as a result, males had significantly lower discrepancy scores at Time $2, F(1,285)=16.77$, $p<.001$.

\section{Change in Self-Concept}

Analyzing change in self-concept for each sex individually using an ANOVA with time as a repeated measures variable, the passage of time between summer orientation and second semester of freshman year was 
associated with a significant increase in real self scores for males, $F(1,127)$ $=15.48, p<.001$. The transition did not bring about a change in males' ideal self scores, nor did it have any effect on females' real or ideal self scores. Probably because of the significant increase in males' real self scores from Time 1 to Time 2, their discrepancy scores decreased over time, $F(1$, $127)=7.90, p<.01$, while females' discrepancy scores did not change.

Due to these sex differences over time, the degree of positive change in real self scores from Time 1 to Time 2 showed a nonsignificant tendency to be greater for males than females, $p<.08$. Moreover, largely because men's real self scores became more positive, a significant sex difference in change in discrepancy scores from Time 1 to Time 2 was apparent, males showing a greater reduction in the gap between real and ideal self than females, $F(1,285)=3.96, p<.05$. Change in ideal self scores from Time 1 to Time 2 was similar in the two sexes; scores were high and did not change much. These results do not bear out hypotheses about males' (H2) and females' (H3) changes in real and ideal self-concept, but do support the hypothesis that males' change in discrepancy would be larger than females' (H4).

\section{Sex Differences in Depression}

We found that females were significantly more depressed than males, both at Time $1, F(1,278)=10.61, p<.001$, and at Time $2, F(1,278)=$ $4.08, p<.05$, supporting our hypothesis [H5]. During seven months between summer orientation and second semester, depression scores increased in both males, $F(1,123)=16.29, p<.001$, and females, $F(1,155)$ $=9.76, p<.01$. The change in depression scores from Time 1 to Time 2 did not differ by sex.

Table II shows that females' depression scores at Time 1 were negatively correlated with their real self scores and positively correlated with their discrepancy scores, as hypothesized (H6), but were not associated with their ideal self scores. Males' depression scores at Time 1 were negatively correlated with their real self scores and ideal self scores but were not associated with their discrepancy scores. At Time 2, both sexes conformed to the hypothesized pattern (H6): There was a negative correlation between depression and real self scores and a positive correlation between depression and discrepancy scores for both males and females.

Tests of the significance of the difference between two independent correlations revealed that the strength of the correlation between depression and self-concept discrepancy scores was greater for females than for males at both Time $1(z=2.43, p<.01)$ and Time $2(z=1.72, p<.05)$, 
Table II. Correlations Between Depression and Self-Concept Scales, by Sex"

\begin{tabular}{lll}
\hline & \multicolumn{2}{c}{ Depression } \\
\cline { 2 - 3 } Scale & Time 1 & Time 2 \\
\hline Real Self & & \\
$\quad$ Females & $-0.26^{d}$ & $-0.57^{d}$ \\
$\quad$ Males & $-0.22^{d}$ & $-0.34^{d}$ \\
Ideal Self & & \\
$\quad$ Females & -0.05 & -0.03 \\
Males & $-0.36^{d l}$ & -0.00 \\
Discrepancy & $0.18^{b}$ & $0.51^{d}$ \\
Females & -0.11 & $0.34^{d}$ \\
Males & & \\
\hline
\end{tabular}

$\bar{a} N=158$ females, 127 males. Time $\mathrm{I}=$ June 1992; Time

$2=$ January 1993 .

${ }^{b} p<.05$.

$c p<.01$.

$a_{p}<.001$.

as hypothesized ( $\mathrm{H} 7)$. Furthermore, the negative correlation between males' depression and ideal self scores was significantly stronger than the corresponding correlation for females at Time $1(z=2.71, p<.01)$, and the negative correlation between depression and real self scores was significantly stronger for females than for males at Time $2(z=2.42, \mathrm{p}<$ $.01)$. Sex differences in the other correlations were nonsignificant.

To explore the implications of changing self-conceptions for well-being, correlations between changes in scores on the self and depression measures were also calculated for each sex. For males, change in depression was negatively correlated with change in real self score $(r=-.21, p<.05)$; that is, those who gained the most in real self-concept were less likely to become depressed over time than those whose changes in real self-concept were less favorable. However, neither the correlation of change in depression with change in ideal self nor that with change in discrepancy was significant for males. For females, an increase in depression was also negatively correlated with an increase in real self score $(r=-.24, p<.01)$. In addition, it was positively correlated with change in discrepancy score $(r=.23, p<$ .01 ); if discrepancy increased over time, so did depression.

\section{One-Year Follow-Up: Sophomore Year}

In order to assess the stability of these findings, and check for a possible weakening of sex differences after the transitional period had ended, 
Table III. Mean Scores on Self Concept and Depression Scales Only for Students Who Responded at All Three Times $(\mathrm{N}=124)^{a}$

\begin{tabular}{lccc}
\hline Scale & Time 1 & Time 2 & Time 3 \\
\hline Real Self & & & \\
$\quad$ Females & $4.91(1.04)$ & $4.98(1.16)$ & $5.19(0.89)$ \\
$\quad$ Males & $4.95(0.83)$ & $5.36(1.04)^{h}$ & $5.26(0.75)$ \\
Ideal Self & & & \\
$\quad$ Females & $6.31(0.65)$ & $6.46(0.71)$ & $6.50(0.64)$ \\
$\quad$ Males & $6.44(0.47)$ & $6.41(0.94)$ & $6.50(0.42)$ \\
Discrepancy & & & \\
$\quad$ Females & $1.40(1.04)$ & $1.48(1.17)^{c}$ & $1.31(0.84)$ \\
$\quad$ Males & $1.49(0.83)$ & $1.05(0.98)$ & $1.23(0.74)$ \\
Depression & $1.94(0.69)^{\prime}$ & $2.06(0.70)$ & $2.20(0.79)$ \\
$\quad$ Females & $1.69(0.55)$ & $1.83(0.73)$ & $1.92(0.59)$ \\
$\quad$ Males & &
\end{tabular}

${ }^{a}$ Statistical comparisons are between males and females within each time point; thus, means should be compared vertically. Time $1=$ June 1992 . Time 2 = January 1993; Time 3 = January 1994; $N=124$ (females $=79$, males $=45)$ for self-concept scales; $N=118($ females $=76$, males $=42)$ for depression scale.

" $p \leq .10$.

$c p \leq .05$.

$p \leq .01$.

' $p \leq .001$.

a follow-up questionnaire (with self-concept and depression scales identical to those on the Time 2 questionnaire) was distributed to the same students at the start of the second semester of their sophomore year (Time 3), one year after they had completed the Time 2 survey. Perhaps hecause this follow-up was not group administered but instead was mailed to students in their dormitories, the response rate was low, reducing the effective $N$ with complete data at all three time points to 124. It should be kept in mind, then, that it is unclear whether the findings here are a result of the passage of time or of the characteristics of the specific subsample of students who filled out the Time 3 survey. For this reason, analyses using the Time 3 data are presented cautiously as a supplement to the main analyses.

Table III reports means and Table IV reports correlations for self-concept and depression among the 45 males and 79 females who responded at all three times. As a qualitative comparison of Tables I and III demonstrates, means for each measure are slightly different when the $N$ is restricted to those participants who completed three surveys. For example, the males who returned the Time 3 survey appear to have more positive ideal self scores than do males who completed only the first two surveys.

When the previous analyses were redone using the reduced sample and looking across all three time points, there were no sex differences in real self, ideal self, or discrepancy scores at Time 3. The sexes seemed to 
Table IV. Correlations Between Depression and Self-Concept Scales Only for Students Who Responded at All Three Times, by Sex ${ }^{a}$

\begin{tabular}{lccl}
\hline & \multicolumn{3}{c}{ Depression } \\
\cline { 2 - 4 } \multicolumn{1}{c}{ Scale } & Time 1 & Time 2 & Time 3 \\
\hline Real Self & & & \\
$\quad$ Females & $-0.41^{d l}$ & $-0.55^{d}$ & $-0.51^{d l}$ \\
$\quad$ Males & $-0.36^{b}$ & -0.17 & $-0.33^{b}$ \\
Ideal Self & & & \\
$\quad$ Females & -0.12 & -0.15 & $-0.36^{d}$ \\
$\quad$ Males & -0.09 & 0.14 & -0.10 \\
Discrepancy & & & \\
$\quad$ Females & $0.33^{c}$ & $0.45^{d}$ & $0.27^{b}$ \\
Males & $0.32^{b}$ & $0.31^{b}$ & 0.28 \\
\hline
\end{tabular}

$" N=$ females, 42 males. Time 1 = June 1992; Time 2 = January 1943; Time

$3=$ January 1994

$b^{\prime} p<.05$.

$c p<.01$.

$d_{p}<.001$.

converge on real self-concept in the year between midfreshman and midsophomore years. Females showed a significant increase in real self-concept between the middle of freshman and the middle of sophomore years, $F(1$, $78)=4.23, p<.05$. This explains the lack of a continued sex difference in real self-concept scores at Time 3. Males' scores did not change significantly from Times 2 to 3 on any of the three scales. Females tended to continue showing more signs of depression than males at Time 3 , but the difference fell short of significance, $F(1,117)=3.78, p<.06$, perhaps because of the smaller sample size. Neither sex showed a significant change in depression from Time 2 to Time 3, although females' depression scores tended to increase $(p<.08)$. Figures 1 and 2 capture the changes in each sex across the transition to college, highlighting Time 2 sex differences in real self-concept and sex differences in symptoms of depression at all 3 time points. Ideal self scores were not graphed as there were no significant sex differences at any time during the transition.

\section{DISCUSSION}

\section{Summary of Results}

In sum, no sex differences in self-concept were found before college, but males' real self-concept became more positive over the transition, making males' change in discrepancy score larger than females', but for different reasons than hypothesized. Females showed more symptoms of 


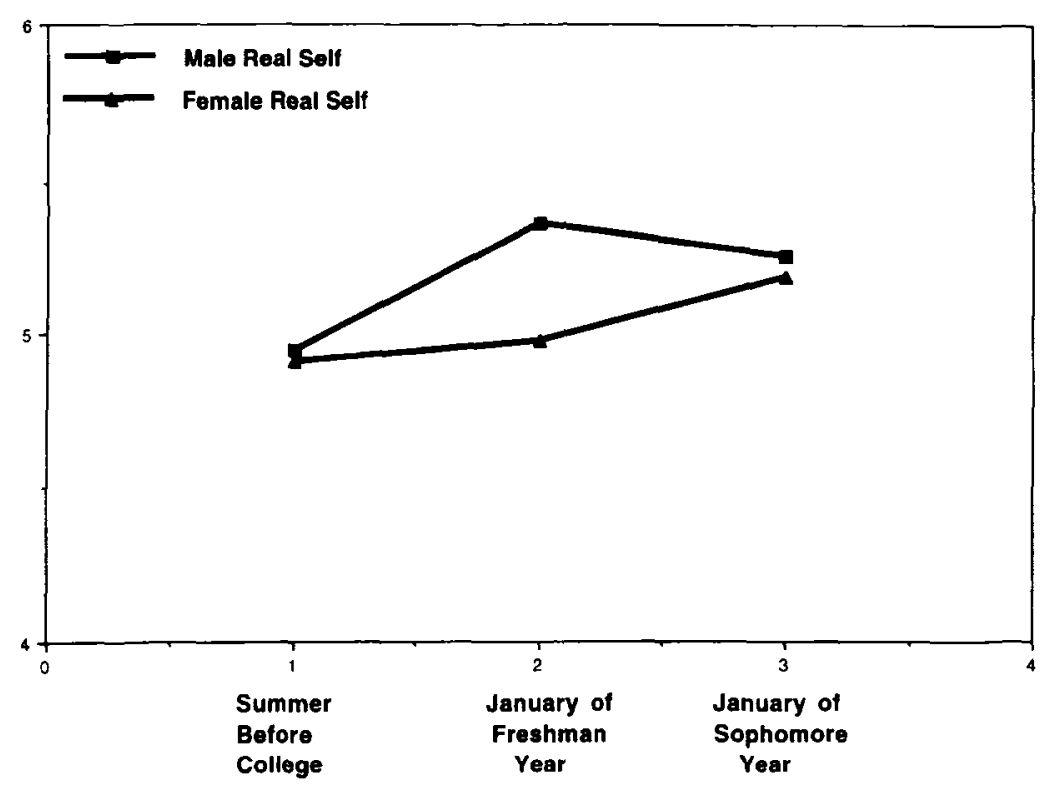

Fig. 1. Change in real-self concept over the transition to college.

depression than males at both times, although both sexes experienced more symptoms of depression over time. Real self-concept scores were negatively correlated with depression in both sexes at both times, while the discrepancy between real and ideal self-concepts was positively correlated with depression among females before college and in both sexes midway through freshman year. Furthermore, the correlations between aspects of self-concept and depression were stronger for females. The one-year follow-up revealed that females' real self-concept scores increased to match those of males by midsophomore year. (To summarize in terms of hypotheses, H1$\mathrm{H} 3$ were not supported, while $\mathrm{H} 4-\mathrm{H} 7$ were supported.)

\section{Implications of the Findings}

\section{Self-Concept}

The lack of sex differences in self-concept at Time 1 contradicts findings from many studies conducted over the past 20 years indicating that males have higher self-esteem than females by the end of high school (e.g., 


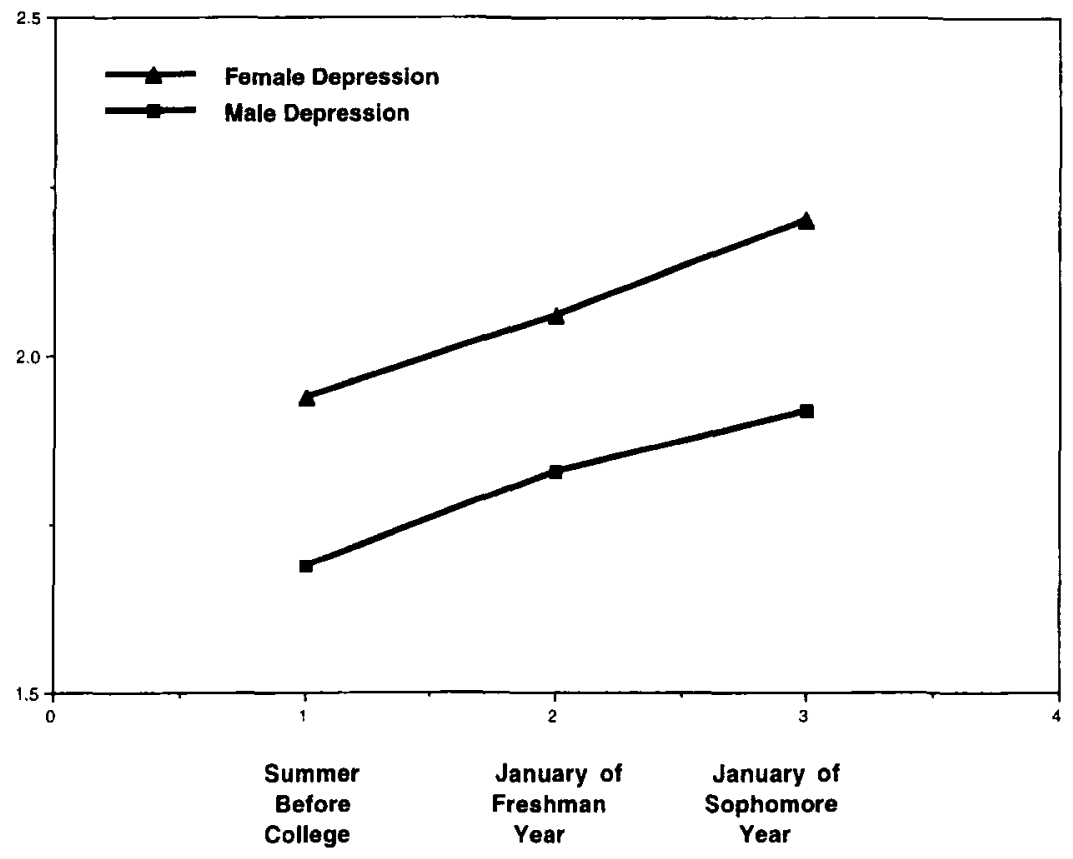

Fig. 2. Change in symptoms of depression over the transition to college.

Block and Robins, 1993; Cairns et al., 1990; Erwin, 1982). Possibly, women in this select sample did not lack confidence, or possibly our measure was insensitive to sex differences. Hypotheses about changes in self-concept over the transition were also not supported; the real self scores of males but not females became more positive from Time 1 to Time 2 . It has been found that academic success holds more importance for males, while interpersonal relationships hold more importance for females (Alishio and Schilling, 1984; Boggiano and Barrett, 1991). It could be that the transition to college produces positive changes in adolescents' academic worlds but disrupts their social worlds, thereby explaining why males' real self-concept scores rose during the transition while females' did not.

Previous research has revealed a general pattern of increased self-esteem over the adolescent years (Block and Robins, 1993; McCarthy and Hoge, 1982), but research on school transitions shows, for the most part, an initial drop in self-esteem following a transition (Eccles et al., 1989; Erwin, 1982; Loeb and Magee, 1992). The finding that males' real self scores rose during the first semester of college while females' remained the same means that neither sex showed the expected drop in real self-concept. Per- 
haps the transition to college is not as difficult as earlier school transitions because students are now older, more psychologically mature, and perhaps less fragile in terms of self-esteem than they may have been in early adolescence. Still, the present findings are not entirely inconsistent with those of studies of the transition to junior high school (Abramowitz et al., 1984; Eccles et al., 1989; Simmons et al., 1987) in the sense that males fared better than females. This finding, along with the Time 3 data, supports a conclusion that the college transition improves the self-perceptions of both sexes, but that females realize the benefits later than males. The results of the one-year follow-up, if generalizable, also help pinpoint when during college sex differences in self-esteem disappear (see Gladstone and Koenig, 1994). We can conclude that, sometime between the middle of freshman and the middle of sophomore year, females "catch up" to males and males "wait up" for females in terms of real self-concept.

\section{Sex Differences in Symptoms of Depression}

Despite this pattern of change in real, though not ideal, self-concept, females showed more symptoms of depression than males at all three times and both sexes reported more symptoms after the transition than before. One the one hand, this sex difference is not surprising, given the abundance of similar findings in the literature (Allgood-Merten et al., 1990; NolenHoeksema, 1990; Petersen et al., 1991). On the other hand, the finding raises questions about the role of self-perceptions in depression because depression scores were negatively correlated with real self scores in both sexes, but there were no sex differences in real self scores at either Times 1 or 3. One possible explanation is that, because young women value interconnectedness more than men do (Alishio and Schilling, 1984; Boggiano and Barrett, 1991), anticipation of and then actual separation from family and friends during the move to college is more difficult for women to weather, which would explain their greater depression at all points during the transition. Indeed, Fisher and Hood (1988) found that females experienced the move to college as more stressful than did males.

Also likely is that females may just have a higher "baseline" level of depression than males throughout adolescence due to some combination of biological and environmental factors (Allgood-Merten et al., 1990; Ge et al., 1994; Petersen et al., 1991; Radloff and Rae, 1979). Nolen-Hoeksema and Girgus (1994), in a review of research on sex differences in adolescent depression, cite such factors as females' more maladaptive attribution and coping styles, weaker instrumental traits, and/or lower assertiveness to explain why girls and women tend to be more depressed than boys and men. 
In contrast to the hypothesis about a higher "baseline" level of depression, this evidence suggests that females' higher levels of depression is due to differential socialization of the sexes, in terms of sex role appropriate ways of dealing with problems or stressors. It has also been noted elsewhere in the literature that females are more likely than males to admit to being depressed, although not by much (Nolen-Hoeksema, 1990).

Despite the fact that females showed more depressive symptoms than males, the present data suggest that any stress associated with the transition to college acts upon both sexes equally; both sexes experienced an increase in depression from Time 1 to Time 2, although depression scores were quite low to begin with. Clearly, other factors besides changes in self-perceptions can contribute to depression and sex differences in depression. For both sexes, new experiences associated with the college environment, such as fear of poor grades, partying too much, dealing with new roommates, and/or being away from home, may produce depressive symptoms even though students may feel the same way or better about themselves as scholars and social beings.

From a developmental perspective, the increase may simply be part of a normal increase in symptoms of depression over the adolescent years (Angold and Rutter, 1992; Brooks-Gunn and Warren, 1989). However, we think it is important to look at students' entire self-system during the transition period, which is why we also look at real and ideal self-concept in conjunction with depression. It is interesting to see what patterns in aspects of self-concept for each sex are correlated with symptoms of depression rather than simply looking at changes in levels of reported depressive symptoms. Thus, despite the possibility that increases in depressive symptoms are normal, we provide a further glimpse about why that may be, particularly at a stressful time in late adolescence. It is not necessarily true that the patterns we found for real and ideal self-concept are following normal trends, and it may be true that different factors affect depression levels at different times. We are suggesting that it is these particular fluctuations of self-concept that we found that are affecting depression levels during the college transition per se.

Another possible reason that depression levels do not return to baseline is that we have underestimated the time it takes to make the transition to college and that, had we measured symptoms of depression again during the students' senior year, or after college, we might have discovered a decrease in symptoms of depression. Unfortunately, we did not follow these students beyond their sophomore year and thus do not have data to show whether the students' depression levels were in fact due to the college transition or not. 


\section{Self-Concept Discrepancy and Symptoms of Depression}

The hypothesis that ideal-real discrepancy scores would be positively correlated with depression scores was largely confirmed. This relationship was observed for females but not males at Time 1. By Time 2, however, both sexes showed the hypothesized positive correlation between depression and discrepancy scores. Gralinski et al. (1995) suggest that their findings of a relationship between self-concept discrepancy scores and depression in adolescents may be attributable to negative internal attributions. If females internalize more than males do (Nolen-Hoeksema, 1990), this may explain both their higher levels of depression and their larger discrepancies between real and ideal self, at least at Time 2; with the college transition acting as an environmental stressor, females may have more negative thoughts about the self to internalize.

The cognitive-developmental perspective states that self-concept discrepancy is both an indicator of maturity (Katz et al., 1975) and a correlate of depressive symptoms (Bybee and Zigler, 1991). Following the argument laid out in the introduction, females would be expected to show large discrepancy scores earlier than males. Although this did not occur, females did demonstrate a correlation between discrepancy and depression carlier than males. Further research on the notion that maturation of the self-concept contributes to increased depression is warranted.

The correlation between ideal-real discrepancy score and depression was also stronger for females than males, as hypothesized. Boggiano and Barrett (1991) discovered that females tend to attribute failures to internal, global, and stable factors to a greater extent than do men. Thus, females may be harder on themselves when they do not "live up to" their ideals (see also Cairns et al., 1990). Indeed, while real self-concept and depression scores were significantly negatively correlated in both sexes at both times, the correlation for females was significantly greater than that for males at Time 2, indicating that young women's depression is more strongly linked with both real self-concept and self-concept discrepancy than is males'. It could be that young men's depression is more strongly related to stressful events in their lives than to their self-evaluations, although Ge et al. (1994) reported that it was among adolescent girls, not boys, that depression hinged more closely on stressful life events. Other factors may be important to the well-being of males, in which case researchers should heed Gladstone and Koenig's (1994) suggestion that males' and females' depression should be regarded as different phenomena. 


\section{CONCLUSION}

This study illuminates sex differences in relationships between self-concept and depression during a developmental transition. A clear message is that men and women respond differently to changes in their environments during adolescent transitions and that these differences in adaptation may not be evident when only overall level of self-esteem is studied. Examining real, ideal, and discrepancy components of self-concept separately has proved fruitful. Sex differences in styles of reacting to environmental changes, exhibited here during the transition to college, appear to have implications for the well-being of young men and women. Examining such sex differences more closely at other ages and in other situations could lead to a greater understanding of problems such as lower self-esteem and greater depression among women than among men (Nolen-Hoeksema and Girgus, 1994). In addition, identifying the sources of increased depression in both sexes during the transition to college could be helpful in designing interventions for new college students.

\section{Limitations}

Whereas this study has contributed to our understanding of the pattern of sex differences in self-concept and depressive symptoms during the transition to college, it also has some limitations that should be noted. First, we used shortened versions of the Sherwood self-concept scale and the Beck depression scale in order to fit them into a longer survey. However, while this may have decreased the scales' validity, the shortened scales were still quite reliable. In addition, the instructions for the Time 2 self-concept scale were changed slightly from the Time 1 format to make them easier to follow. However, all of the items and response scales remained exactly the same at the two times, and any influences of the changed format would have had to have affected both sexes equally.

Second, as mentioned earlier, not all of the entering students at this university fully completed their surveys at both Times 1 and 2, which reduced the effective sample size substantially. Even fewer completed the Time 3 survey as sophomores, but Nielson et al. (1978) point out that it is difficult to avoid selection bias in follow-up studies of college students. The students who participated in this study may be more conscientious or more compliant than the entering class as a whole, but in terms of gender and ethnic breakdowns they were still representative. Furthermore, our sample was clearly affluent; a qualitative examination of the incomes and education of the parents of students in our study suggest that they may be of a higher 
socioeconomic status than the average college student in this country, which may be due to the fact that the university is private.

Finally, we were not able to examine self-concept and depression in a comparable noncollege sample. However, our purpose was to examine the effect of the college transition, which only required a college sample. Still, we agree with Sherrod et al. (1993) that it is unfortunate that so little research on this developmental period in general compares college and noncollege samples.

\section{Suggestions for Future Research}

Future research on sex differences in self-concept and depression during the transition to college should be able to provide a comparison to noncollege populations in order to determine whether the patterns we have found are due to the transition to college itself or merely to normal developmental changes.

It may also prove useful in future research to study sex differences in satisfaction with the new college environment in relation to satisfaction with the high school environment. Eccles and colleagues (1993) point out in their review of the impact of school transitions that adjustment may suffer if the individuals' needs are not met by a new environment. While an "arena of comfort" is necessary to prevent stress, Simmons et al. (1987) also suggest that too much environmental stability may result in a failure to grow and learn. Eccles and Simmons agree that the impact on students of school transitions in early adolescence depends on the degree of continuity between the two school environments. They also agree that individuals differ in their developmental readiness for the transition and that paying attention to these differences may be key in preventing the early loss of self-esteem in girls. Research on this issue during the college transition would be highly interesting as well.

This study has several significant strengths. First, few studies of the transition to college include precollege data. Second, few studies examine the relationships between real and ideal self-concept and depression longitudinally. And third, it is rare that studies that do either or both of the above also examine sex differences.

In conclusion, the current study's findings of sex differences in selfconcept and depression during the transition to college suggest that the need for research in this area has not yet been exhausted. Even though members of both sexes may experience substantial growth and change during adolescence, and even if efforts are made to give them equal oppor- 
tunities to do so, there is no guarantee that new experiences will be integrated into the self-systems of young men and women in similar ways.

\section{ACKNOWLEDGMENTS}

The authors would like to thank Cheryl Beil, C. Ellen Peters, and Phillip Wirtz for their assistance. We also appreciate the useful comments of Susan Nolen-Hoeksema on an earlier draft of this manuscript.

\section{REFERENCES}

Abramowitz, R. H., Petersen, A. C., and Schulenberg, J. E. (1984). Changes in self-image during early adolescence. New Direct. Mental Health Sen. 22: 19-28.

Alishio, K. C., and Schilling, K. M. (1984). Sex differences in intellectual and ego development in late adolescence. J. Youth Adolesc. 13: 213-224.

Allgood-Merten, B., Lewinsohn, P. M., and Hops, H. (1990). Sex differences and adolescent depression. J. Abnormal Psychol. 9: 55-63.

Angold, A., and Rutter, M. (1992). Effects of age and pubertal status on depression in a large clinical sample. Develop. Psychopathol. 4:5-28.

Bardwick, J. M. (1971). A Study of Bio-Cultural Conflicts. Harper \& Row, New York,

Barone, C., Aguirre-Deandreis, A. I., and Trickett, E. J. (1991). Means-ends problem-solving skills, life stress, and social support as mediators of adjustment in the normative transition to high school. Am. J. Commun. Psychol. 19:207-225.

Beck, A. (1967). Depression: Clinical, Experimental, and Theoretical Aspects. Harper \& Row, New York.

Beil, C. (1992). The Chilly Climate for GW Undergraduate Women. Unpublished manuscript, The George Washington University, Washington, DC.

Blatt, S., D'Afflitti, J., and Quintan, D. (1976). Experiences of depression in normal young adults. J. Abnormal Psychol. 85: 383-389.

Block, J., and Robins, R. W. (1993). A longitudinal study of consistency and change in selfesteem from early adolescence to early adulthood. Child Develop. 64: 909-923.

Boggiano, A. K., and Barrett, M. (1991). Gender differences in depression in college students. Sex Roles 25: 595-605.

Brooks-Gunn, J., and Warren, M. P. (1989). Biological and social contributions to negative affect in young adolescent girls. Child Develop. 60: 40-55.

Bybee, J. A., and Zigler, E. (1991). Self-image and guilt: A further test of the cognitive-developmental formulation. J. Personal. 59: 733-745.

Cairns, E., McWhirter, L., Duffy, U., and Barry, R. (1990). The stability of self-concept in late adolescence: Gender and situational effects. Personal. Indiv. Diff. 11: 937-944.

Cantor, N., Norem, J. K., Niedenthal, P. M., Langston, C. A., and Brower, A. M. (1987). Life tasks, self-concept ideals, and cognitive strategies in life transition. J. Personal. Social Psychol. 53: 1178-1191.

Eccles, J. S. (1987). Gender roles and women's achievement-related decisions. Psychol.Women Quan. 11: 135-172.

Eccles, J. S., Midgley, C., Wigfield, A., Buchanan, C. M., Reuman, D., Flanagan, C., and Mac lver, D. (1993). The impact of stage-environment fit on young adolescents' experiences in schools and in families. Am. Psychol. 48: 90-101. 
Eccles, J. S., Wigfield, A., Flanagan, C. A., Miller, C., Reuman, D. A., and Yee, D. (1989). Self-concepts, domain values, and self-esteem: Relations and changes at early adolescence. J. Personal. 57: 283-310.

Erikson, E. (1968). Identity: Youth and Crisis. W. W. Norton, New York.

Erwin, T. D. (1982). Academic status as related to the development of identity. J. Psychol. 110: $163-169$.

Fisher, S., and Hood, B. (1988). Vulnerability factors in the transition to university: Self-reported mobility history and sex differences as factors in psychological disturbance. $B r . J$. Psychol. 79: 309-320.

Garg, R. (1992). Academic and nonacademic self-concepts: Influence of recent life-change experiences and demographic, social, and health variables. Psychol. Rep. 70: 871-882.

Ge, X., Lorenz, F. O., Conger, R. D., Elder, G. H., and Simons, R. L. (1994). Trajectories of successful life events and depressive symptoms during adolescence. Develop. Psychol. 30: $467-483$.

Gladstone, T. R. G., and Koenig, L. J. (1994). Sex differences in depression across the high school to college transition. J. Youth Adolesc. 23: 643-669.

Gralinksi, J. H., Safyer, A. W., Hauser, S. T., and Allen, J. P. (1995). Self-cognitions and expressed negative emotions during midadolescence: Contributions to young adult psychological adjustment. Develop. Psychopathol. 7: 193-216.

Groër, M. W., Thomas, S. P., and Shoffner, D. (1992). Adolescent stress and coping: A longitudinal study. Res. Nurs. Health 15: 209-217.

Handal, P. J., Gist, D. C., and Wiener, R. L. (1987). The differential relationship between attribution and depression for male and female college students. Sex Roles 16: 683-88.

Hesse-Biber, S. and Marino, M. (1991). From high school to college: Changes in women's self-concept and its relationship to eating problems. J. Psychol. 125: 199-216.

Higgins, E. T. (1987). Self-discrepancy: A theory relating self and affect. Psychol. Rev. 94: 319-340.

Higgins, E. T., Klein, R., and Strauman, T. (1985). Self-concept discrepancy theory: A psychological model for distinguishing among different aspects of depression and anxiety. Social Cogn. 3: 51-76.

Hirsch, B. J., and Rapkin, B. D. (1987). The transition to junior high school: A longitudinal study of self-esteem, psychological symptomatology, school life, and social support. Child Develop. 58: 1235-1243.

Hood, A. B., Riahinejad, A. R., and White, D. B. (1986). Changes in ego identity during the college years. J. College Student Person. 27: 107-113.

Katz, P. A., Zigler, E., and Zalk, S. R. (1975). Children's self-image disparity: The effects of age, maladjustment, and action-thought orientation. Develop. Psychol. 11: 546-550.

Loeb, R. C., and Magee, P. M. (1992). Changes in attitudes and self-perceptions during the first two years of college. J. College Student Develop. 33: 348-355.

McCarthy, J. D., and Hoge, D. R. (1982). Analysis of age effects in longitudinal studies of adolescent self-esteem. Develop. Psychol. 18: 372-379.

Nielson, H. D., Moos, R. H., and Lee, E. A. (1978). Response bias in follow-up studies of college students. Res. Higher Educat. 9: 97-113.

Nolen-Hoeksema, S. (1990). Sex Differences in Depression. Stanford University Press, Stanford, CA.

Nolen-Hoeksema, S., and Girgus, J. S. (1994). The emergence of gender differences in depression during adolescence. Psychol. Bull. 115: 424-443.

O'Connor, J. L. (1978). Perceptions of self, ideal self, and teacher feelings in preadolescent children. Elem. School Guid. Counse. 13: 88-92.

Petersen, A. C., Sarigiani, P. A., and Kennedy, R. E. (1991). Adolescent depression: Why more girls? J. Youth Adolesc. 20: 247-271.

Radloff, L. S., and Rae, D. S. (1979). Susceptibility and precipitating factors in depression: Sex differences and similarities. J. Abnomal Psychol. 88: 174-181.

Rosenberg, M. (1986). Self-concept from middle childhood through adolescence. In Suls, J., and Greenwald, A. (eds.), Psychological perspectives on the self (Vol. 3) Lawrence Erlbaum Associates, Hillsdale, NJ. 
Schludermann, S., and Schludermann, E. (1986). Sociocultural change and adolescents' attitudes toward themselves and others. Int. J. Behav. Develop. 9: 129-152.

Sherrod, L. R., Haggerty, R. J., and Featherman, D. L. (1993). Introduction: Late adolescence and the transition to adulthood. J. Res. Adolesc. 3: 217-226.

Sherwood, J. J. (1965). Self identity and referent others. Sociometry 28: 66-81.

Simmons, R. (1987). Social transition and adolescent development. New Direc. Child Develop. 37: 33-61.

Simmons, R. G., Burgeson, R., Carlton-Ford, S., and Blyth, D. A. (1987). The impact of cumulative change in early adolescence. Child Develop. 58: 1220-1234.

Stewart, A. J., Sokol, M., Healy, J. M, and Chester, N. L. (1986). Longitudinal studies of psychological consequences of life changes in children and adults. J. Personal. Social Psychol. 50: 143-151.

Wigfield, A., Eccles, J. S., Mac Iver, D., Reuman, D. A., and Midgley, C. (1991). Transitions during early adolescence: Changes in children's domain-specific self-perceptions and general self-esteem across the transition to junior high school. Develop. Psychol. 27: 552-565. 